\title{
RESEARCH ON MULTI-AGENT SYSTEMS IN A SMART SMALL GRID FOR RESOURCE APPORTIONMENT AND PLANNING
}

\author{
ZHIXIAN YANG, KSHUANGCHEN FU $†$ AND JHON PAUL
}

\begin{abstract}
With the advancement in the technology, deployment of sensors in the industrial or public building is increasing rapidly. The basic aim is to obtain the data from the environment and decision making to the energy saving. The activities caused by the human results the undergoing negative change in the environment. There are many techniques available for decision making and consider the environmental factors solely which cause the energy consumption. However, user's preferences are not adapted by the systems, but at energy consumption optimization, these systems are very successful. The end-users use the system which considers the factors and their wellbeing are get affected. The distributed generation is incorporated by the Smart Small Grid (SSG), communication network and the sensors for the more reliable, flexible and efficient grid. The energy saving system is presented in this paper which also adapts to the inhabitants preferences apart from environmental conditions consideration. The architecture of Multi-Agent System (MAS) and the agents are utilized for negotiation process performance between the users comfort preferences and optimization degree that according to these preferences, achievement of system is done. The energy consumption of $40 \%$ is obtained and in the inhabitants' behavior pattern, the algorithm was specialized. The $16.89 \%$ of reduction is obtained by the existing system and it was focused to obtain the agreement between the system and users for user preference satisfaction and the energy optimization is also performed at the same time.
\end{abstract}

Key words: Multi-Agent System; Energy Saving; Consumption Optimization; Environmental Factors; Industrial or Public Building

AMS subject classifications. 93A16

1. Introduction. The smooth and clean electric power is delivered by the smart small grid (SSG), the generators, archival and certain control units are comprised in it. The SSG is low voltage network, usually situated at the side of consumer [1,2]. There is rapid increment of the electric power in the recent years for fulfillment of the daily basis needs. The sources of renewable energy are very efficient and the distributed generation sources control is also very effective with power storage devices. The renewable sources practice is increasing and taken attention in modern smart electric power grids as there is great demand of the electrical power [3]. The utilization of the renewable energy sources are utilized normally as they are eco-friendly. For the renewable energies, the fast technological growth is utilized for making the system more economical and for under-developing countries; the import of fossil fuels is reduced. The electrical energy is generated by the renewable energy resources at lower price. Without any environmental hazards, the living standards are improved $[4,5]$. In supporting the distributed electrical network, it plays important role in the remote areas. In 2010, the wind energy generation's investment rate is very high, then reduction occurred in the next years but maintained till 2015. In the solar energy investment rate, the problem occurred after a year by wind power in contrast [6]. So, there is reduction again in the renewable energy generation investment rate during 2010 and 2014 but then again maintained in 2015. The several projects are funded by the different countries in spite of economic problems for the renewable energy sources connection to the power grids. The different energy sources are combined in the SSG like small wind turbines, and integration of the micro turbines with storage devices, like batteries connected at low voltage systems [7, 8]. For electric power distribution, there is installation of the different protection systems at every feeder. The basic hybrid MG architecture is depicted in Fig 1.1.

The distributed generation is incorporated by the SSG, communication network and the sensors for the more reliable, flexible and efficient grid. The reconsider of traditional power system operations is required by

*Zhengzhou Railway Vocational and Technical College, Zhengzhou, China (Zhixianyang11@outlook.com).

${ }^{\dagger}$ Zhengzhou Railway Vocational and Technical College, Zhengzhou, China (Shuangchenfu28@outlook.com ).

$\ddagger$ University Malaysia Pahang, Malaysia (psm19008@stdmail.ump.edu.my). 


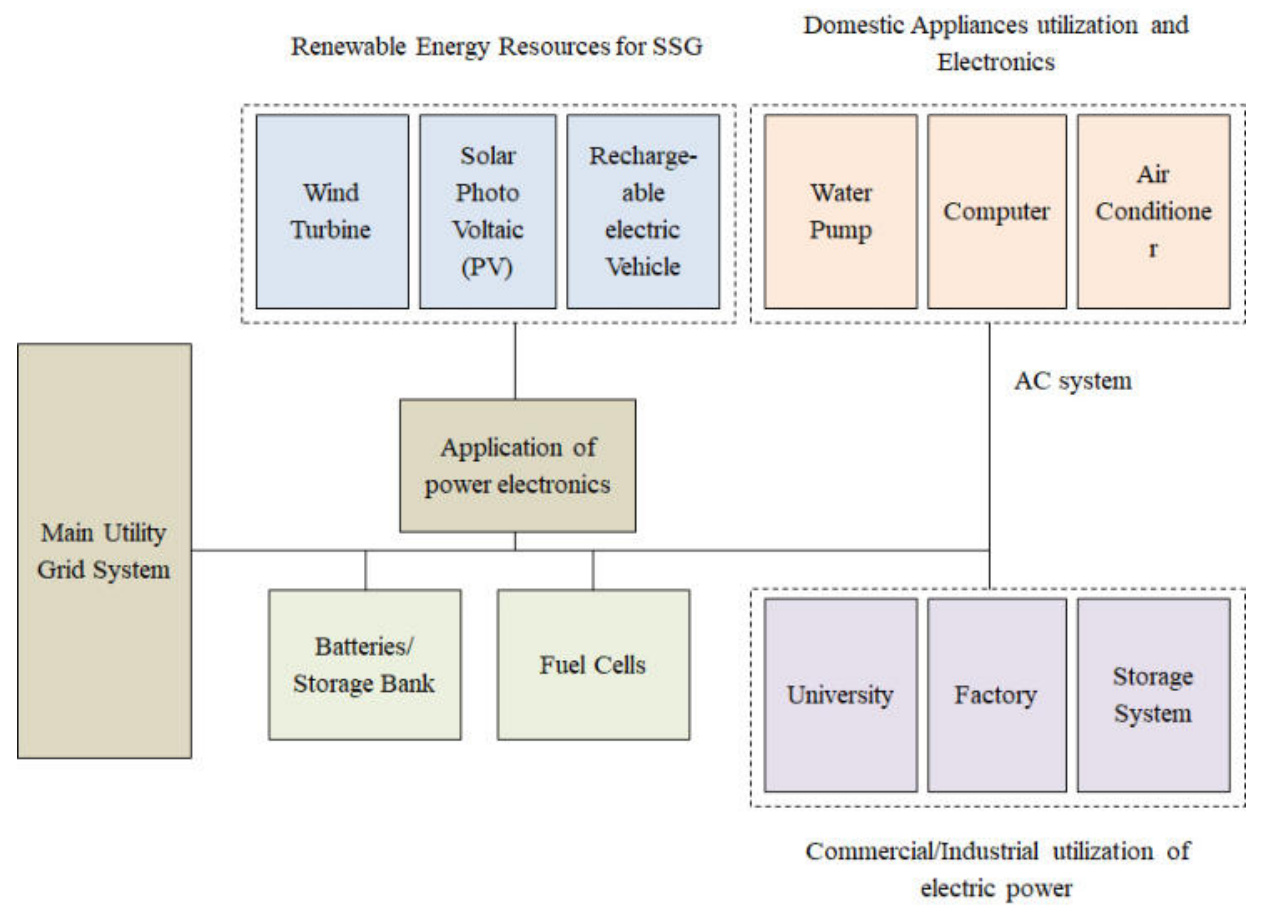

FIG. 1.1. The basic hybrid $M G$ architecture

the power system paradigm for distribution systems and next-generation transmission. The competition is created in the energy market for power generation companies along with renewable energy sources integration [9]. The allocation of the generation sources is required properly for maximizing the profit by considering the customer demand. The many technological challenges are created by the increased Renewable Energy Sources (RES) penetration for the power companies to maintain the power quality to consumers. The power generation is maintained by the mixture of conventional and RES at the required level $[10,11]$. The generators and allocating the required generation level commitment process has challenge to meet the increased demand. The centralized control is made by these factors and less effective for the data diversity and controls process [12]. The Multi-Agent Systems (MAS) concept solves this problem by utilizing the automated agent methods. At a component level, the centralized control system is converted by MAS into a distributed control model. According to rules and regulations, the numbers of objects are met by designing the MAS. A set of agents are integrated by an MAS system for communicate, coordinate and interaction for the objects establishment. The way referred by the self-coordination in which objective of consuming less resource are achieved by the system co-operations and also it consumes fewer resources. The communication plays very significant role in the MAS $[13,14]$. The communication and self-organization's basic principles are maintained. An environment, objects and agents are consisted in the MAS and the entities performs a set of operations. The control schemes MAS ability prediction like artificial intelligence techniques and there is an additional advantage of expert system analysis hybrid controllers in SSGs. The MAS system incorporation becomes very easier, faster and feasible. The productions of distributed generators (DG) are enhanced and the electric power exchange is considered for optimization of the interconnected SSG operation [15]. The load demand of network is fulfilled by utilizing the MAS in the management system. This paper contributes the energy saving system which also adapts to the inhabitants preferences apart from environmental conditions consideration. The architecture of MAS and the agents are utilized for negotiation process performance between the users comfort preferences and optimization degree that according to these preferences, achievement of system is done. The MAS concept solves this problem by utilizing the automated agent methods. At a component level, the centralized control system is converted by MAS into a distributed control model. 
The organization of rest of the paper is as follows. Section II provides an overview of the exhaustive literature survey is provided in section II followed by a research methodology adopted in section III. The obtained results are discussed in section IV. Finally, Section V concludes the paper.

The distributed generation is incorporated by the SSG, communication network and the sensors for the more reliable, flexible and efficient grid. The reconsider of traditional power system operations is required by the power system paradigm for distribution systems and next-generation transmission. The competition is created in the energy market for power generation companies along with renewable energy sources integration [9]. The allocation of the generation sources is required properly for maximizing the profit by considering the customer demand. The many technological challenges are created by the increased Renewable Energy Sources (RES) penetration for the power companies to maintain the power quality to consumers. The power generation is maintained by the mixture of conventional and RES at the required level $[10,11]$. The generators and allocating the required generation level commitment process has challenge to meet the increased demand. The centralized control is made by these factors and less effective for the data diversity and controls process [12]. The Multi-Agent Systems (MAS) concept solves this problem by utilizing the automated agent methods. At a component level, the centralized control system is converted by MAS into a distributed control model. According to rules and regulations, the numbers of objects are met by designing the MAS. A set of agents are integrated by an MAS system for communicate, coordinate and interaction for the objects establishment. The way referred by the self-coordination in which objective of consuming less resource are achieved by the system co-operations and also it consumes fewer resources. The communication plays very significant role in the MAS $[13,14]$. The communication and self-organization's basic principles are maintained. An environment, objects and agents are consisted in the MAS and the entities performs a set of operations. The control schemes MAS ability prediction like artificial intelligence techniques and there is an additional advantage of expert system analysis hybrid controllers in SSGs. The MAS system incorporation becomes very easier, faster and feasible. The productions of distributed generators (DG) are enhanced and the electric power exchange is considered for optimization of the interconnected SSG operation [15]. The load demand of network is fulfilled by utilizing the MAS in the management system. This paper contributes the energy saving system which also adapts to the inhabitants preferences apart from environmental conditions consideration. The architecture of MAS and the agents are utilized for negotiation process performance between the users comfort preferences and optimization degree that according to these preferences, achievement of system is done. The MAS concept solves this problem by utilizing the automated agent methods. At a component level, the centralized control system is converted by MAS into a distributed control model.

The organization of rest of the paper is as follows. Section 2 provides an overview of the exhaustive literature survey is provided in section II followed by a research methodology adopted in section 3 . The obtained results are discussed in section 4 . Finally, Section 5 concludes the paper.

2. Literature Review. In this paper, a distributed micro-grid control system (DCS) framework is proposed for micro-grid assets control which includes the loads and the point of interconnection [16]. For controlling micro-grid assets, the technique is proposed including distributed energy resources. A multi-agent system is employed by the design where each asset is assigned an agent. The DCS capability of meeting micro-grid dispatch is demonstrated by this work. The optimization of controllable distributed energy resources is done at maximum power point tracking. The different load types, sizes, and costs are considered to carry out the distributed load curtailment. The sourcing of critical commands is centralized by the features of the control system during emergency events. Reinforcement Learning, the electricity prices are fluctuating increasingly by the growing share of renewable power generation. To the volatile prices on the markets, energy demand of production processes is adapted to reduce the electricity expenses [17]. The new paradigm of energy flexibility is depicted by this approach for electricity costs reduction. The possibilities for decreasing energy costs are offered by utilizing the electricity self-generation. The battery storage and self-generation are included in the manufacturing system and the supply side. Due to unforeseen events, a complex optimization problem is represented by the coordination which is stochastic. An approach to controlling a complex system is presented in this system by utilizing the multi-agent reinforcement learning (MARL). The developed system is demonstrated in the study that outperforms the rule-based reactive control strategy (RCS). The state-of-the-art developments in MASs are reviewed in this article and this methodology contributed in various paradigms utilized in energy 
optimization [18]. This paper describes the different types of agent-based architectures and analyzed the role played by the environment. For various purposes, the utilization of MASs is considered in this paper. The multi-agent systems are utilized in the energy optimization field to model energy efficiency solutions. To reduce the CO2 emission, the green energy technologies is adopted in the Micro-grid (MG). The solar photo voltaic (PV) [19]. The power system evolves the distributed energy resources, such as solar photo voltaic (PV), diesel engines, small wind turbines and fuel cell technologies. There is a great effect of this power maintenance on power systems. The main focus of this article is on MAS technologies for MG control and its optimization. The centralized and decentralized approach comparison is also detailed in this paper. Scalable Multi-Agent System (MAS) for operation of a Microgrid in islanded mode, scalable MAS is presented. An intelligent agent in MAS represents the autonomous element in the micro-grid [20]. The power production of local distributed generators is maximized by the MAS and the operational cost of microgrid subject is minimized. The objective of microgrid operation is done after the interaction of agents in MAS and the Power World simulator is utilized and no technical violation is confirmed. The studies present and demonstrate the proposed MAS effectiveness for microgrid optimal operation and also show autonomous built-in simulation of microgrids possibility. MASs for Resource Allocation and Scheduling in a Smart Grid For scheduling and allocation of resources in a smart grid, integration of Distributed Energy Resources (DER) is increasing in power grid [21]. The major resource allocation problems are Economic Dispatch (ED) and Unit Commitment (UC) in grid system. The resource allocation problems become more challenging by the renewable energy sources. The development of a decentralized approach is necessitating by the complex smart grid system and inter-node communication is allowed by it. The traditional centralized resource allocation aspects are decentralized by the MAS. Multi agent system: concepts, platforms and applications in power systems. The vital changes are experienced by the power system and it is advancing from centralized structure to a decentralized [22]. The new requirements are fulfilled by the systems and the restricted data transfer capacity for communications. Through the connection of these agents, accomplishment of degree of distributed or collective intelligence is done. A comprehensive survey on the power system applications is provided in this paper.

3. Proposed Methodology. In this section, the MAS-based architecture is presented which allows the measures simulation to obtain an optimization of energy. The lower energy consumption user provides the previous technologies synergies without sacrificing comfort in non-invasive way. There are three aspects in which the system should be focused.

1. Knowledge and learning.

2. The environment Communication, analysis and adaptation.

3. Decision making

There are two aspects that are the user knowledge and the environment knowledge on which the knowledge capacity is granted by the agents $[23,24]$. The use knowledge means knowing all the user aspects which affect the energy consumption like preferences, habits, and timetables in the building. On the other hand, knowledge of the environment means the building's exterior temperature is required to be known like solar incidence, weather forecast. The previous data analysis will provide the MAS information which is utilized for the environment adaptation. The MAS capacity of self-adaptation allows the system to behave in deterministic way regardless of the context and the users are allowed for the detection of external consumption factors which influence consumption of energy, without having to make complex configurations [25]. The standard communication protocols are developed by the agents that allow the communication with the HVAC and lighting. Through the user's knowledge, the devices are completely and independently interacted by the system. It is necessary to deploy wireless sensor networks (WSN) in multi-story office building and the problems are presented that the ability to observe dynamic scenes by controlling the changes in status and the configuration [26, 27]. Different types of the problem are managed by the system by deploying the agents that utilized the techniques of Information Fusion (IF). The more precise data and estimates obtained from the individual or multiple sources. The management of the WSN user is facilitated by the system in which the complex configurations have not been performed. The goal of optimizing energy is achieved by the MAS with greater intelligence with the highest possible result. For the conception of technical development, the GAIA method has been utilized and this method focus on the software system design based on the agent's intelligent. This technique facilitating the problems solution that arises in the development and the main jobs utilized in MAS. The decomposition 


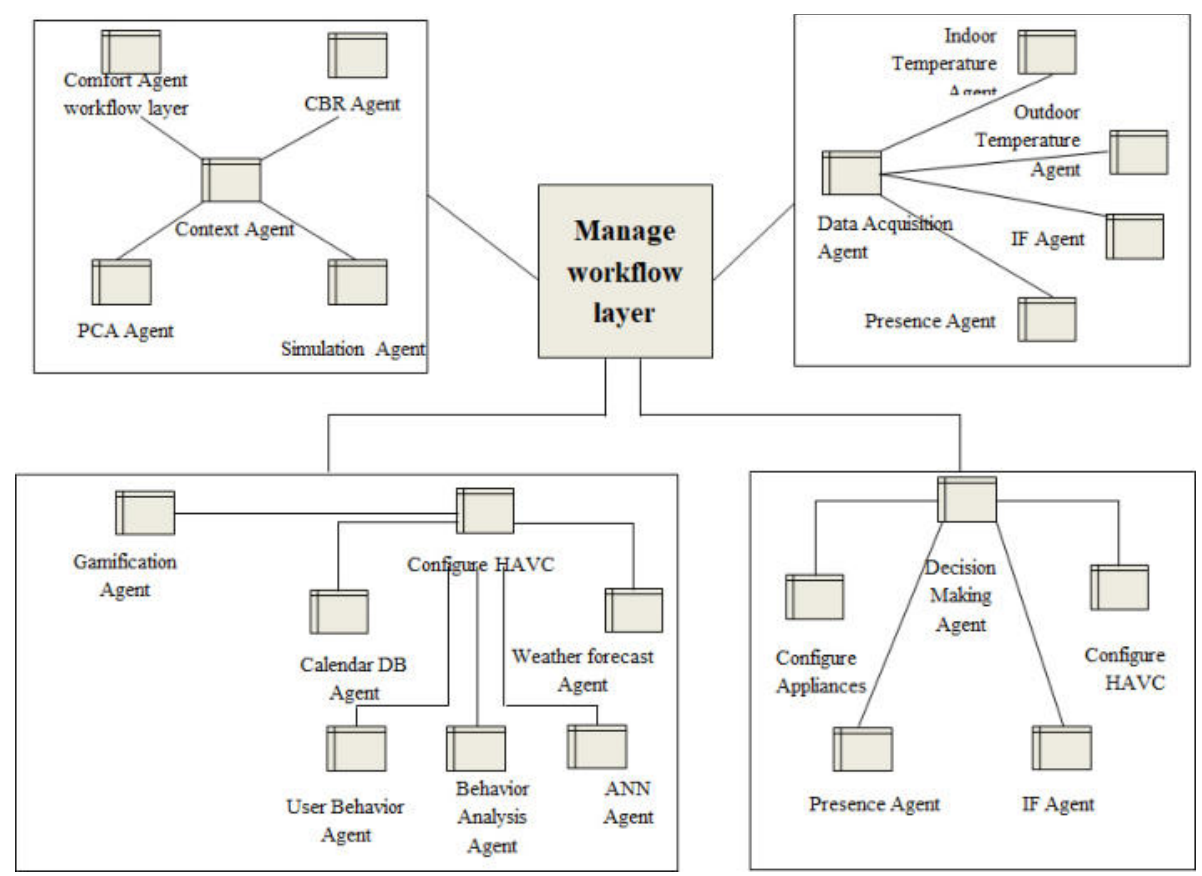

FIG. 3.1. Architecture divided in layers according to the functionality of agents that integrate them

of problem into sub-problems is very important. The layers are formed by different agents which encloses the system functionality. This structure of organizational is made according to the activities affinity that each of them performs, as shown in Figure 3.1.

Simulation Layer: The system's behavior is simulated by the layers which allow the term establishment and according to this the energy optimization is performed. The characteristics of environment are collected by the context agent and deployment of the system is done. A series of parameters are set by the Principal Component Analysis (PCA) agent in which optimization decisions are done and the parameters are obtained. The agent of this layer implements AI techniques and a case-based reasoning system (CBR) [28]. The previous optimization cases are collected by the system that allows us to obtain the consumption optimization. The simulation execution is allowed by the simulation agent by coordinating the system agents. The consumption data possibility is offered by it and WSN's each sensor collected in real time.

Manage Workflow Layer: The agents make up the system are coordinated by this agent and between the different parties, it established the communication [29]. The correct order for the each agent activity is allowed by this communication establishment. The need to automate actions is responded by the agent's inclusion which responds to frequent events.

WSN Data Acquisition Layer: The responsibility of data collection from the environment is on this layer. The external temperature and interior data are obtained by the agents of WSN data acquisition layer [30]. The data collection frequency is set by the data acquisition agent. Through a middleware, communication with the sensors is also established by this layer.

Knowledge Information Layer: The optimization activities are modeled by the information layer and the data from the WSN Data Acquisition Layer is also obtained. The behavior patterns of the IB users are analyzed by utilizing the behavior analysis agent [31]. The behavior patterns of the IB users is known and allowed the user behavior agent together with the gamification Agent.

Action Layer: The information from the other layers is utilized for making decision by this layer. The HVAC system, appliances configuring agent and configuration of consumption mode are configured by the agents [32]. 
TABLE 4.1

Energy consumption results in the different experimental periods

\begin{tabular}{||l|l|l|l|l||}
\hline Simulations & Baseline Period $(\mathrm{Wh})$ & Simulation Period $(\mathrm{Wh})$ & Difference $(\mathrm{Wh})$ & Savings (\%) \\
\hline \hline Simulation 1 & 25.89 & 21.28 & 3.56 & 14.66 \\
\hline Simulation 2 & 25.89 & 21.12 & 3.84 & 15.93 \\
\hline Simulation 3 & 25.89 & 21.07 & 3.98 & 16.08 \\
\hline
\end{tabular}

4. Results and Discussion. The system implementation results are described in this paper in the working environment (smart buildings) since one of the system objective is to be self-adaptive to the building characteristics. The validation of the different technologies coupling is the presented work purpose which is utilized in the different area of energy utilization. The different methodologies are integrated by multi agent system in the data management from WSN. The energy consumption data is obtained by the MAS if it was to be deployed in a household simulation. The two phases are consisting in the experiment. First is the baseline period in the first phase and the electrical consumption is monitored by the MAS. Each person's timetables are learnt and all the indoor and outdoor temperatures $(\circ \mathrm{C})$ recorded. The simulation period is the second phase in which conditions of the baseline period is recreated for the proposal MAS efficiency evaluation. The optimization decisions made in the second phase made by the Decision Making Agent and the first phase conditions have been recreated. The decisions are made by the agent of decision making according to the comfort knowledge of the users. The climatic conditions are known in the first phase under which HVAC system temperature is modified by the users. The CBR system is implemented by the agents that predict the people presence and absence in home and adjust the HVAC system temperature. Lowering the temperature is consisted in the temperature settings when no one in the house and when inhabitants returns home, temperature increasing progressively. The database are connected to the agents from where it is obtained that the days are non-working. These agents have cooperation and it is possible to know which days the inhabitants may or may not spend on the floor. The system doesn't require the PCA agent as problem dimensions are very few which have been addressed.

The environment data is obtained by the mechanism in the architecture through a WSN. The simulation of the decision making is done although the communication with HVAC system is provided by designing the architecture. The system's increase, decrease, and turning on or off are allowed by the system. The device connection with the MAS system simulation is done by utilizing the IoT devices. The CBR system is implemented by the agent incorporation in addition to several technologies conjunction. The learning behavior pattern is allowed by it along with other variables. Through the floor schedules knowledge, translation is done into energy savings and schedules are learnt for intelligent thermostats programming. The MAS agents learning capacity incorporates and allowed a data analysis and automatically performed it. The system checked the data collection before new analysis which is same as of previous analyses. The system effectiveness is verified by the case study simulation and the consumption of $25.89 \mathrm{Wh}$ is obtained in the baseline period. The maximum rate of $21.28 \%$ is achieved by the MAS system by carried out the simulations and user behavior recreation. The HVAC system is better adjusted by the CBR in each simulation stores. The results of each simulation are shown in Table 4.1 and presented graphically in Figure 4.1.

The consumption of energy is notably lower in the case study as presented in Table 4.2. It ensures that the decision for temperature reduction and devices are turned off when there is no one at home and energy consumption reduction is provided. The graphical representation is shown in Figure 4.2 for better visualization.

4.1. Comparison of the presented work with the existing technique. The effectiveness of the presented technique is shown by comparing the technique with the existing work. The energy consumption in terms of mean value is compared with the existing work which is obtained from the presented technique. The mean obtained from the presented technique is little less as compared to the existing techniques both in baseline period and evaluation period. The obtained mean values for baseline and evaluation period are tabulated in Table 4.3. For better analysis and visualization, it is also presented graphically in Figure 4.3.

The comparison is also done in terms of standard deviation of the existing and presented technique in terms of baseline period and evaluation period. The obtained standard deviation values for baseline and evaluation 


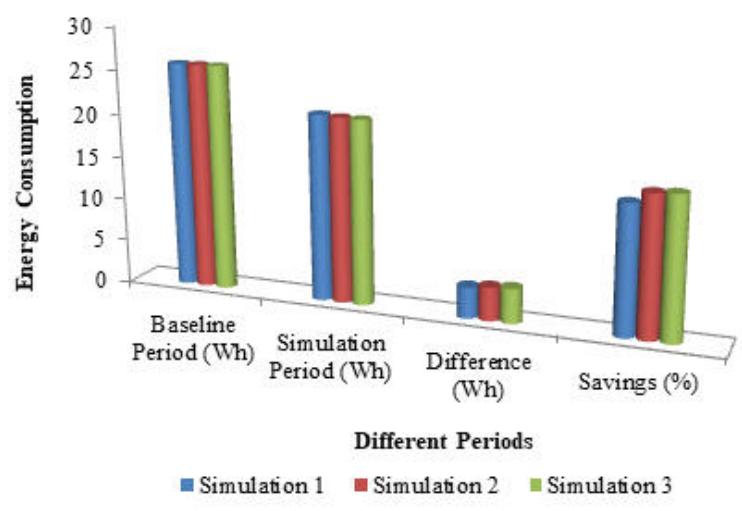

FIG. 4.1. Energy consumption results in the different experimental periods

TABLE 4.2

Difference of means and variances between the baseline period and the evaluation period of the simulations

\begin{tabular}{|c|c|c|c|c|}
\hline Simulations & $\begin{array}{l}\text { Baseline Period } \\
(\mathrm{Wh})(\text { Mean value } \\
(\mathrm{kWh}))\end{array}$ & $\begin{array}{l}\text { Baseline } \begin{array}{r}\text { Period } \\
(\mathrm{Wh})\end{array} \text { (Standard } \\
\text { Deviation }(\mathrm{kWh}))\end{array}$ & $\begin{array}{l}\text { Evaluation Period } \\
(\text { Mean }(\mathrm{kWh}))\end{array}$ & $\begin{array}{l}\text { Evaluation Pe- } \\
\text { riod (Standard } \\
\text { Deviation }(\mathrm{kWh}))\end{array}$ \\
\hline Simulation 1 & 25.89 & 1.48 & 21.28 & 1.76 \\
\hline Simulation 2 & 25.89 & 1.48 & 21.12 & 1.54 \\
\hline Simulation 3 & 25.89 & 1.48 & 21.07 & 1.43 \\
\hline
\end{tabular}

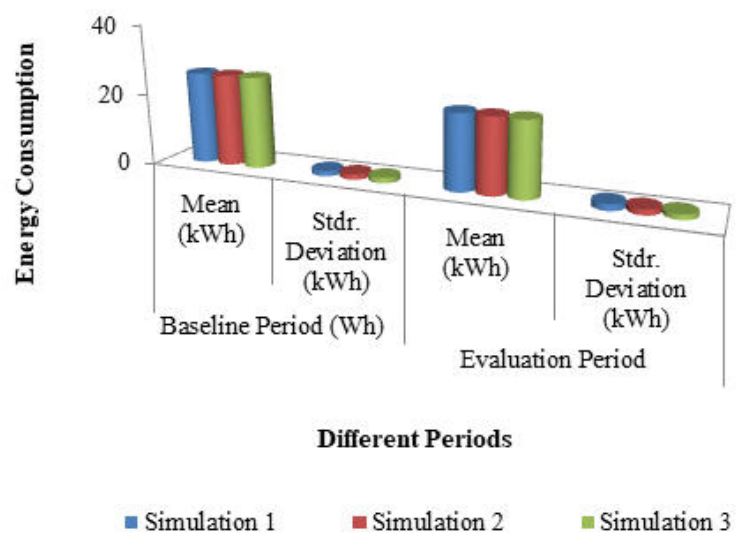

FIG. 4.2. Means and variances between the baseline and evaluation period

period are tabulated in Table 4.4. It is obtained from the table that the values calculated from the existing technique are more as compared to the presented technique. There are not that much variation in the obtained values from the existing and the presented technique. Graphical representations of the obtained values are shown in Figure 4.4 for better visualization and analysis purpose.

The percentage difference of the presented technique and the existing technique is also calculated to see the exact difference between the two techniques. The percentage difference is calculated for baseline and evaluation period for existing and presented techniques in terms of mean and standard deviation which are the main parameters. The obtained values are presented in Table 4.5 and also presented graphically in Figure 4.5 for 
TABLE 4.3

Comparison of presented and existing techniques in terms of Mean value

\begin{tabular}{||l|l|l|l|l||}
\hline Simulations & $\begin{array}{l}\text { Existing Technique } \\
\text { (Baseline Period } \\
(\mathrm{Wh}))\end{array}$ & $\begin{array}{l}\text { Existing Tech- } \\
\text { nique (Evaluation } \\
\text { Period) }\end{array}$ & $\begin{array}{l}\text { Proposed Tech- } \\
\text { nique (Baseline } \\
\text { Period (Wh)) }\end{array}$ & $\begin{array}{l}\text { Proposed Tech- } \\
\text { nique (Evaluation } \\
\text { Period) }\end{array}$ \\
\hline \hline Simulation 1 & 26.19 & 22.33 & 25.89 & 21.28 \\
\hline Simulation 2 & 26.19 & 22.09 & 25.89 & 21.12 \\
\hline Simulation 3 & 26.19 & 22.01 & 25.89 & 21.07 \\
\hline
\end{tabular}

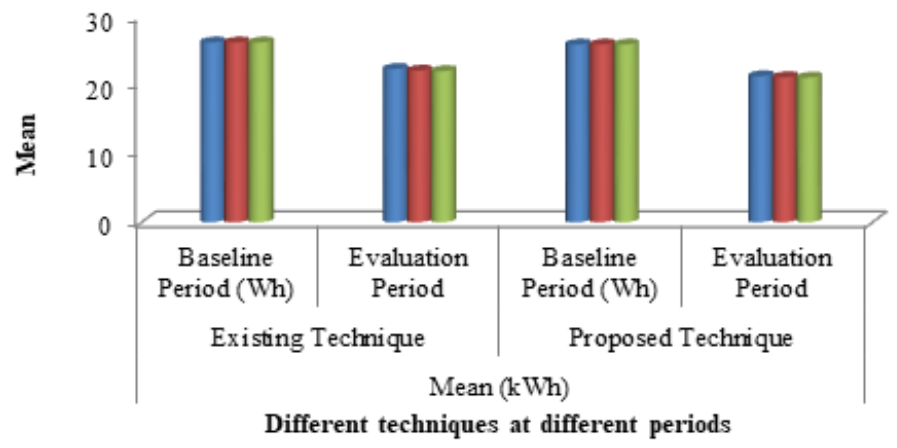

nSimulation 1 Simulation 2 Simulation 3

FIG. 4.3. Comparison of presented and existing techniques in terms of mean value

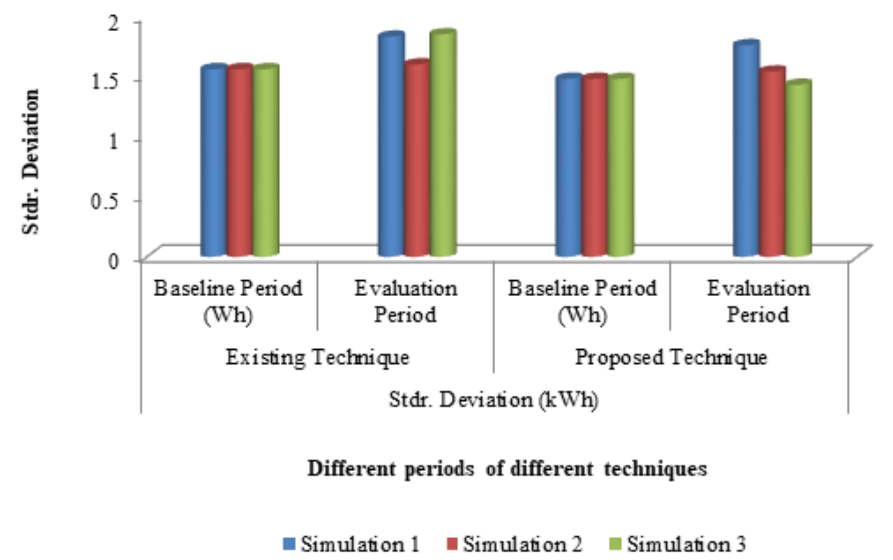

FIG. 4.4. Comparison of presented and existing techniques in terms of standard deviation value

better analysis and visualization.

The results obtained by the presented techniques and the existing techniques are compared and it is found that the values are comparable in both the techniques in form of mean and standard deviation. The energy consumption of $40 \%$ is obtained and in the inhabitant's behavior pattern, the algorithm was specialized. The $16.89 \%$ of reduction is obtained by the existing system and it was focused to obtain the agreement between the system and users for user preference satisfaction and the energy optimization is also performed at the same time. 
TABle 4.4

Comparison of presented and existing techniques in terms of standard deviation value

\begin{tabular}{||l|l|l|l|l||}
\hline Simulations & $\begin{array}{l}\text { Existing Technique } \\
\text { (Baseline Period } \\
(\mathrm{Wh}))\end{array}$ & $\begin{array}{l}\text { Existing Tech- } \\
\text { nique (Evaluation } \\
\text { Period) }\end{array}$ & $\begin{array}{l}\text { Proposed Tech- } \\
\text { nique Proposed } \\
\text { Period (Wh)) }\end{array}$ & $\begin{array}{l}\text { Tech- } \\
\text { nique } \\
\text { Period) }\end{array}$ \\
\hline \hline Simulation 1 & 1.56 & 1.83 & 1.48 & 1.76 \\
\hline Simulation 2 & 1.56 & 1.60 & 1.48 & 1.54 \\
\hline Simulation 3 & 1.56 & 1.85 & 1.48 & 1.43 \\
\hline
\end{tabular}

TABLE 4.5

Percentage Difference between the presented and existing technique in terms of mean and standard deviation

\begin{tabular}{|c|c|c|c|c|}
\hline $\begin{array}{l}\text { Percentage } \\
\text { Difference }\end{array}$ & $\begin{array}{l}\text { Mean (Baseline Pe- } \\
\operatorname{riod}(\mathrm{Wh}))\end{array}$ & $\begin{array}{l}\text { Mean (Evaluation } \\
\text { Period) }\end{array}$ & $\begin{array}{lr}\text { Stdr. } & \text { Deviation } \\
(\mathrm{kWh}) & (\text { Baseline } \\
\text { Period }(\mathrm{Wh}))\end{array}$ & $\begin{array}{lr}\text { Stdr. } & \text { Deviation } \\
(\mathrm{kWh}) & \text { (Evaluation } \\
\text { Period) } & \end{array}$ \\
\hline Simulation 1 & $1.16 \%$ & $4.93 \%$ & $5.41 \%$ & $3.98 \%$ \\
\hline Simulation 2 & $1.16 \%$ & $4.59 \%$ & $5.41 \%$ & $3.90 \%$ \\
\hline Simulation 3 & $1.16 \%$ & $4.46 \%$ & $5.41 \%$ & $29.3 \%$ \\
\hline
\end{tabular}

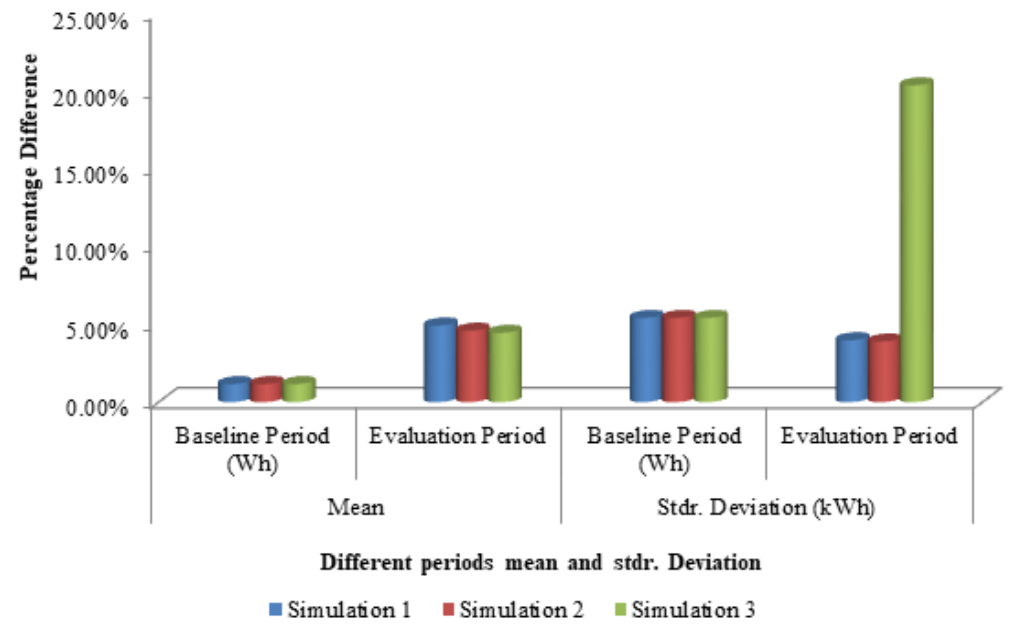

FIG. 4.5. Percentage difference between the presented and existing technique in terms of mean and standard deviation

5. Conclusion. The presented MAS concept solves this problem by utilizing the automated agent methods. At a component level, the centralized control system is converted by MAS into a distributed control model. According to rules and regulations, the numbers of objects are met by designing the MAS. A set of agents are integrated by an MAS system for communicate, coordinate and interaction for the objects establishment. The way referred by the self-coordination in which objective of consuming less resource are achieved by the system co-operations and also it consumes fewer resources. A WSN has been implemented in the agents within the multi-agent system developed. The environmental data is collected by the WSN to make it possible to meet needs of users' comfort. The negotiation process is performed between the user preferences and the system's decisions. The MAS is capable of monitoring and negotiating through the agent's deployment. The energy consumption of $40 \%$ is obtained and in the behavior pattern of the inhabitants, the algorithm was specialized. The $16.89 \%$ of reduction is obtained by the existing system and it was focused to obtain the agreement between the system and users for user preference satisfaction and the energy optimization is also performed at the same 
time. The architecture of MAS and the agents are utilized for negotiation process performance between the users comfort preferences and optimization degree that according to these preferences, achievement of system is done.

\section{REFERENCES}

[1] Nunna, H. K., Saklani, A. M., Sesetti, A., Battula, S., Doolla, S., And Srinivasan, D., Multi-agent based demand response management system for combined operation of smart microgrids, Sustainable Energy, Grids and Networks, 6 , 25-34, 2016.

[2] Brazier, F., La Poutre, H., Abhyankar, A. R., Saxena, K., Singh, S. N., And Tomar, K. K., A review of multi agent based decentralised energy management issues, . In 2015 International Conference on Energy Economics and Environment (ICEEE) (pp. 1-5). IEEE, 2015.

[3] 3. Kong, X., LiU, D., XiaO, J., And WAng, C. , A multi-agent optimal bidding strategy in microgrids based on artificial immune system, Energy, 189, 116154, 2019.

[4] González-Briones, A., De La Prieta, F., Mohamad, M. S., Omatu, S., and Corchado, J. M. , Multi-agent systems applications in energy optimization problems: A state-of-the-art review, Energies, 11(8), $1928,2018$.

[5] Oey, M. A., Genc, Z., Ogston, E., And Brazier, F. M., Symphony-agent-based platform for distributed smart grid experiments, In International Conference on Practical Applications of Agents and Multi-Agent Systems (pp. 238-249). Springer, Cham, 2014.

[6] Martin, R., Christian, L., Roland, Z., Andreas, R., Andrea, H., and Gunther, R. , Smart Grid for Industry Using Multi-Agent Reinforcement Learning, Applied Sciences, 10(19), 6900, 2020.

[7] Patel, S., Khatana, V., Saraswat, G., and Salapaka, M. V., Distributed detection of malicious attacks on consensus algorithms with applications in power networks, In 20207 th International Conference on Control, Decision and Information Technologies (CoDIT) (Vol. 1, pp. 397-402). IEEE, 2020.

[8] Brazier, F., Ogston, E., And Warnier, M. , The future of energy markets and the challenge of decentralized selfmanagement, In Agents and Peer-to-Peer Computing (pp. 95-103). Springer, Berlin, Heidelberg, 2009.

[9] Pouttu, A., Hadpola, J., Ahokangas, P., Xu, Y., Kopsakangas-Savolainen, M., Porras, E., ... And Casado, S., P2P model for distributed energy trading, grid control and ICT for local smart grids, In 2017 European Conference on Networks and Communications (EuCNC) (pp. 1-6). IEEE.

[10] Khan, B., And Singh, P., Selecting a meta-heuristic technique for smart micro-grid optimization problem: A comprehensive analysis, IEEE Access, 5, 13951-13977, 2017.

[11] Ellabban, O., And ABu-Rub, H. , Smart grid customers' acceptance and engagement: An overview, Renewable and Sustainable Energy Reviews, 65, 1285-1298, 2016.

[12] Bragg-Sitton, S. M., Boardman, R., Rabiti, C., Suk Kim, J., McKellar, M., Sabharwall, P., ... And Qualls, A. L. , Nuclear-renewable hybrid energy systems: 2016 Technology development program plan, Idaho National Lab.(INL), Idaho Falls, ID (United States); Oak Ridge National Lab.(ORNL), Oak Ridge, TN (United States).

[13] Bragg-Sitton, S. M., Boardman, R., Rabiti, C., Suk Kim, J., McKellar, M., Sabharwall, P., ... And Qualls, A. L. Nuclear-renewable hybrid energy systems: 2016 Technology development program plan, Idaho National Lab.(INL), Idaho Falls, ID (United States); Oak Ridge National Lab.(ORNL), Oak Ridge, TN (United States).

[14] Khan, B., AND Singh, P. , Economic operation of smart micro-grid: a meta-heuristic approach, In Handbook of research on smart power system operation and control (pp. 330-346). IGI Global, 2019.

[15] 15. O'Malley, G., Wu, J., And Jenkins, N. , Technical requirements of smart electric power distribution networks in the UK, In 45th International Universities Power Engineering Conference UPEC2010 (pp. 1-6). IEEE, 2010.

[16] Al Jajeh, M. F. , Microgrid Management Using a Distributed Multi-Agent Control System, McGill University (Canada).

[17] Martin, R., Christian, L., Roland, Z., Andreas, R., Andrea, H., and Gunther, R., Smart Grid for Industry Using Multi-Agent Reinforcement Learning, Applied Sciences, 10(19), 6900, 2020.

[18] González-Briones, A., De La Prieta, F., Mohamad, M. S., Omatu, S., And Corchado, J. M. , Multi-agent systems applications in energy optimization problems: A state-of-the-art review, Energies, 11(8), 1928, 2018.

[19] Khan, M. W., AND Wang, J. , The research on multi-agent system for microgrid control and optimization, Renewable and Sustainable Energy Reviews, 80, 1399-1411, 2017.

[20] Logenthiran, T., Srinivasan, D., Khambadkone, A. M., And Aung, H. N., Scalable multi-agent system (MAS) for operation of a microgrid in islanded mode, In 2010 Joint International Conference on Power Electronics, Drives and Energy Systems and 2010 Power India (pp. 1-6). IEEE.

[21] Nair, A. S., Hossen, T., Campion, M., Selvaraj, D. F., Goveas, N., KaAbouch, N., And Ranganathan, P., Multiagent systems for resource allocation and scheduling in a smart grid, Technology and Economics of Smart Grids and Sustainable Energy, 3(1), 1-15, 2018.

[22] Sujil, A., Verma, J., And Kumar, R., Multi agent system: concepts, platforms and applications in power systems, Artificial Intelligence Review, 49(2), 153-182, 2018.

[23] Murray, W., Adonis, M., and Raji, A., Voltage control in future electrical distribution networks, Renewable and Sustainable Energy Reviews, 146, 111100, 2021.

[24] Tan, Z., Cheng, L., Zhao, Y., Xu, C., And Yu, T., System architecture design for coordinated-control of large-scale distributed equipment in energy universal service bus system, In 2017 3rd IEEE International Conference on Computer and Communications (ICCC) (pp. 2775-2785). IEEE. 
[25] Crispim, J., Braz, J., Castro, R., and Esteves, J., Smart Grids in the EU with smart regulation: Experiences from the UK, Italy and Portugal, Utilities Policy, 31, 85-93, 2014.

[26] Bowring, E., Tambe, M., and Yokoo, M., Balancing local resources and global goals in multiply-constrained DCOP , Multiagent and Grid Systems, 6(4), 353-393, 2010.

[27] Feng, Y., Hong, Z., Zhang, Z., Zhang, Z., and Tan, J., Interval analysis and DEMATEL-based reliability apportionment for energy consumption optimization with energy Internet, IEEE Access, 5, 4769-4778,2017.

[28] Silva, C., Faria, P., And Vale, Z. , Demand response and distributed generation remuneration approach considering planning and operation stages, Energies, 12(14), 2721,2019.

[29] Han, S., Zhang, S., CaO, J., Wen, Y., And Zhang, Y., A resource aware software partitioning algorithm based on mobility constraints in pervasive grid environments, . Future Generation Computer Systems, 24(6), 512-529,2008.

[30] Mukhopadhyay, B., And Das, D. , Multi-objective dynamic and static reconfiguration with optimized allocation of PV-DG and battery energy storage system, Renewable and Sustainable Energy Reviews, 124, 109777,2020.

[31] Smart, L. S., Vukomanovic, J., Sills, E. O., and Sanchez, G., Cultural ecosystem services caught in a coastal squeeze between sea level rise and urban expansion, Global Environmental Change, 66, 102209,2021.

[32] Hussain, M. M., Alam, M. S., And Beg, M. S., Fog computing model for evolving smart transportation applications, Fog and Edge Computing: Principles and Paradigms, 22(4), 347-372,2019.

Edited by: Pradeep Kumar Singh

Received: May 26, 2021

Accepted: Sep 20, 2021 
